\title{
Italian Economics Departments' Scientific Research Performance: Comparison between VQR and ASN Methodologies
}

\author{
Gennaro Guida ${ }^{1}$ \\ ${ }^{1}$ Department of Economic and Legal Studies, University Parthenope, Naples, Italy \\ Correspondence: Gennaro Guida, ${ }^{1}$ Department of Economic and Legal Studies, University Parthenope, Naples, \\ Italy. E-mail: gennaro.guida@uniparthenope.it
}

Received: June 7, 2018

doi:10.5539/ijbm.v13n9p182
Accepted: July 20, 2018

Online Published: August 2, 2018

URL: https://doi.org/10.5539/ijbm.v13n9p182

\begin{abstract}
The aim of this article is to investigate whether there are important differences between the evaluation procedures adopted by the Italian Ministry of Education, University, and Research in the evaluation of scientific research. The two procedures, one for the periodic exercise of the evaluation of scientific research activities and the other to verify the possession of the requisites necessary to be employed as a professor at a university, have different purposes and have been implemented with different evaluation approaches. Analysing sample data extracted from the well-known Scopus database, we replicate the assessment methodologies, obtaining some interesting results. The two procedures identify the same departments of excellence and draw similar rankings. The two evaluation criteria are not so far apart in the identification of the departments of excellence. Through the use of coloured maps, we then identify that the distribution of the departments of excellence in the national territory favours the northern regions.
\end{abstract}

Keywords: Academic institutions; citations; research performance

\section{Introduction}

In December 2010, Law 240/2010, commonly known as the 'Reform Gelmini', taking the name of the Minister of Education, University, and Scientific Research, was approved. This new law made several changes to the old system. Among the most important are, first, the implementation of a periodic exercise of evaluation of scientific research activities undertaken by universities and research institutions (known as the Valutazione della Qualità della Ricerca, VQR) and, second, a new recruitment system capable of selecting first- and second-level professors, which provides a national procedure aimed at verifying the possession of the requisites (in terms of scientific papers, conferences, etc.) necessary to be employed as a professor at a university (known as the Abilitazione Scientifica Nazionale, ASN). These are two procedures that have different purposes and that have been implemented with different evaluation approaches. Both, however, substantially measure the quality of scientific publications produced within Italian universities. Although the VQR, in fact, has this as its primary purpose, even the results of the ASN, as it was conceived and implemented, can be interpreted as an attempt to measure the quality of academics' research. For this reason, it is interesting to try to compare the outcomes of the two procedures and determine whether, as we would expect, the framework of the Italian academic research that these procedures return is similar as regards the evaluation of the excellent products of the departments, taking into account the fact that the ASN involves a smaller number of younger researchers, since it does not affect those who are already qualified and who occupy higher roles in their university career and at the same time it evaluates, more importantly, the publications in national journals, for which, otherwise, using only bibliometric parameters, they would be excessively penalized.

To achieve this goal, we require data on the scientific publications produced by Italian academics. We therefore use a sample of bibliometric data and indexes, reproducing the evaluation of research in Italy, limiting ourselves to identifying only excellent publications (those appearing in the so-called band A), and comparing these results with the values of excellence expected in the evaluation exercise aimed at qualification. From the comparison of the rankings obtained by the two procedures, we draw some significant information.

The work is divided into sections: the second section contains a brief review of the literature and the legal aspects concerning the two procedures, the third discusses the sample data and the results obtained by the economics departments of Italian universities, and finally the conclusions are presented. 


\section{Methodology to Assess Scientific Research}

In Italy, over the last ten years, great importance has been attached to the new agency created to assess scientific research. This agency, the ANVUR (National Agency for Assessing University and Scientific Research), was established in 2006 to perform the following functions:

1. External assessment of the quality of activities of universities and public and private research organizations receiving public funding on the basis of an annual programme approved by the Ministry of Education, University, and Scientific Research;

2. Addressing, coordinating, and monitoring the evaluation activities carried out in the internal assessment cores of universities and research entities;

3. Evaluation of the efficiency and effectiveness of state funding programmes and of the incentives to undertake research and innovation activities.

Through the Assessment of Scientific Research (VQR), the ANVUR measures the validity of the results of the scientific research carried out in the past three years by state and non-state universities and private entities that engage in research activity. The evaluation of scientific research performance is carried out with different methods according to the scientific sectors involved. The most-used technique, however, is the informed peer review. This technique consists of evaluating some of the works with the classic peer review and some with the most common bibliometric indicators. The pros and cons of the peer review and bibliometric methods have been thoroughly dissected in the literature (Abramo \& D'Angelo, 2011; Horrobin, 1990; MacRoberts \& MacRoberts, 1996; Moed, 2002; Moxam \& Anderson, 1992; Pendlebury, 2009; van Raan, 2005).

In our work, we analyse research products published by professors belonging to the statistical economic sector (the so-called Area 13); however, we submit these products, which constitute the sample to analyse, to bibliometric evaluation only, taking into account the following consideration: the ANVUR conducts an "experiment", submitting about $5 \%$ of the journal articles to a double evaluation, both through bibliometric analysis and through peer review, to verify the concordance of the results obtained by the two techniques. The appendix to the final report clearly indicates that the results obtained with the two techniques are different (ANVUR, 2013). For all the disciplinary sectors, the degree of concordance (Cohen's kappa coefficient) calculated by the ANVUR is between 0.17 and 0.35, which means (Landis \& Koch, 1977) a degree of concordance between the results of the two techniques that can be defined as limited or moderate. The statistical economic sector represents an exception with a relatively high concordance index (0.68). This observation allows us to reproduce the results of the VQR through a sample of products of Area 13 only through bibliometric indicators. Summing up, the choice to dwell only on products of the statistical economic area is based on two considerations: the aforementioned similarity between the peer review evaluation and that carried out through bibliometric indicators and the territorial diffusion of the economics faculties, which allows us to draw conclusions that involve the entire national territory.

The national scientific qualification certifies the status that is a necessary requirement for selection for access to the first and second classes of professors' careers. For Area 13, the object of our analysis, the Ministry of Education, University, and Scientific Research (MIUR), indicates an evaluation of scientific products achieved by aspiring professors through non-bibliometric indexes. In this way, the Ministry publishes a list of scientific journals that are evaluated as excellent. As mentioned previously, the need to protect the language and the dissemination of Italian articles and journals clashes with the use of bibliometric indexes, which favour articles and journals in English, which can boast more citations and can be addressed to a much wider scholarly audience (see the discussions in van Leeuwen, Moed, Tijssen, Visser, \& van Raan, 2001; van Raan, 2009). The language bias is one of the main reasons for the exclusion of bibliometric evaluation for scientific qualification.

The evaluation of scientific publications for aspiring professors is aimed at ascertaining:

a) for the functions of professor belonging to the first class, the full scientific maturity of the candidate, attested by the importance of the scientific issues addressed and the achievements of results of relevant quality and originality, such as to confer a position recognized in the international research community;

b) for the functions of second-class professor, the maturity of scientific knowledge of the candidate, understood as the recognition of a positive level of quality and originality of results achieved in the research addressed and such as to give a position recognized at least in the national scientific research community.

The difference between being qualified as a first-class professor and being qualified as a second-class professor lies in the prestige that can be obtained if circumscribed to the national sphere or extended to the international one. In the first case, therefore, those products published in national journals had to be considered. If these 
journals were to be evaluated through bibliometric indexes, the products published in those journals would be penalized, hence the need to entrust the evaluation of scientific journals to the same Ministry through a non-bibliometric evaluation. The Ministry will indicate the list of magazines that it considers to be excellent.

The following work aims to verify the results obtained from the evaluation of scientific research on the departmental level, comparing the rankings produced by the different evaluation procedures to check whether they both identify the same departments of excellence. To reach this goal, in the next section, we examine a sample of scientific products published in the last 10 years by professors of economics employed by Italian universities. It should be recalled that the performance results of the departments under analysis are easily comparable, since in the Italian university system there is not a strong distinction between teaching-oriented universities and research-oriented universities.

\section{Data Set and Results}

To rank the departments of economics, we consider a sample of products published in the period 2007-2016, evaluating them with the two methods described in the previous session. Scopus and Web of Science are two of the world's largest abstracting and citation databases. The publishing corporation Elsevier currently owns Scopus, which covers 69.2 million documents. Clarivate Analytics owns Web of Science. Its key database, the Web of Science Core Collection, contains 66.7 million documents. Scopus and Web of Science have their advantages and limitations for the different aspects of quantitative scientometric analysis (e.g. Archambault, Campbell, Gingras, \& Larivière, 2009; Bakkalbasi, Bauer, Glover, \& Wang, 2006; Deis \& Goodman, 2005; Falagas, Pitsouni, Malietzis, \& Pappas, 2008; Kotsemir \& Shashnov, 2017; Li, Burnham, Lemley, \& Britton, 2010; Meho \& Yang, 2006; Shashnov \& Kotsemir, 2015; Vieira \& Gomes, 2009). A key advantage of Scopus for our analysis is the presence of the system of unique author and organization identifiers (profiles). The user can thus analyse the publication activity of organizations, while this possibility is not readily available in the Web of Science.

We analyse a sample of about 4,000 articles published by professors of economics employed in Italian universities. In the database, we can distinguish the so-called class A top journals that represent excellence of the published products. Therefore, we build two classifications, limiting ourselves to considering in tabular form only the first 30 departments (out of a total of over 200) but taking them all into account in the maps that will follow. The ranking carried out through the list of journals included in class A, according to the criteria used for the ASN, counts the products included in the sample belonging to this class. A different methodology is used to build the ranking based on bibliometric parameters adopted by the VQR. In this case, for the evaluation of the performance of scientific research, reference is made to the following four bibliometric indices: the Impact Factor, calculated over a period of 5 years (IF5); the Impact per Publication (IPP), the Scimago Journal Ranking (SJR), and the Article Influence Score (AIS). The classification procedure ensures that an article falls into class A (excellent) if it is included in the top $10 \%$ of the distribution of international scientific production in the area to which it belongs. As it can happen that an article has an evaluation of excellence for one index, being included in the top $10 \%$, and not for another, we use the bibliometric parameters typical of the VQR, considering as class A an article for which at least one of the bibliometric indicators falls into that class.

Table 1. Bibliometric Indexes Used in the VQR

\begin{tabular}{|c|c|}
\hline Index's denomination & How it is derived \\
\hline Impact Factor, five years & $\begin{array}{l}\text { The IF measures the average number of citations received in a particular year from articles published in a scientific } \\
\text { journal in the previous five years. }\end{array}$ \\
\hline $\begin{array}{l}\text { Scimago } \\
\text { Ranking }\end{array}$ & $\begin{array}{l}\text { This is a measure of scientific influence of scholarly journals that accounts for both the number of citations received } \\
\text { by a journal and the importance or prestige of the journals that contain such citations. The SJR indicator's } \\
\text { computation is carried out using an iterative algorithm that distributes prestige values among the journals until a } \\
\text { steady-state solution is reached. The SJR algorithm begins by allocating an identical amount of prestige to each } \\
\text { journal and then using an iterative procedure; this prestige is redistributed in a process whereby journals transfer } \\
\text { their achieved prestige to each other through citations. The process ends when the difference between journal } \\
\text { prestige values in consecutive iterations no longer reaches a minimum threshold value. }\end{array}$ \\
\hline Impact per Publication & $\begin{array}{l}\text { The IPP corresponds to the average number of citations received in a year from articles published in the magazine } \\
\text { over the past three years. }\end{array}$ \\
\hline Article Influence Score & $\begin{array}{l}\text { The Article Influence Score measures the average influence of articles in the journal and is therefore comparable to } \\
\text { the traditional impact factor. }\end{array}$ \\
\hline
\end{tabular}


The table below shows the ranking of the departments, from which the results can be compared.

Table 2. Ranking of Departments

\begin{tabular}{|c|c|c|c|}
\hline University & Department & Ranking VQR & Ranking ASN \\
\hline ROMA Tor Vergata & Dip. Economia e Finanza & 1 & 2 \\
\hline BOLOGNA & Dip. Scienze Economiche & 2 & 1 \\
\hline PADOVA & Dip. Scienze Economiche e Aziendali "Marco Fanno" & 3 & 3 \\
\hline MILANO Bocconi & Dip. Economia & 4 & 14 \\
\hline PISA & Dip. Economia e Management & 5 & 4 \\
\hline VENEZIA Ca' Foscari & Dip. Economia & 6 & 7 \\
\hline ROMA TRE & Dip. Economia & 7 & 5 \\
\hline BOLOGNA & Dip. Scienze Aziendali & 8 & 6 \\
\hline MILANO Bicocca & Dip. Economia, Metodi Quantitativi e Strategie d'Impresa & 9 & 13 \\
\hline NAPOLI Federico II & Dip. Scienze Economiche e Statistiche & 10 & 18 \\
\hline SIENA & Dip. Economia Politica e Statistica & 11 & 19 \\
\hline MODENA e REGGIO EMILIA & Dip. Economia "Marco Biagi" & 12 & 36 \\
\hline TORINO & Dip. Scienze Economico-Sociali e Matematico-Statistiche & 13 & 8 \\
\hline PAVIA & Dip. Scienze Economiche e Aziendali & 14 & 11 \\
\hline MILANO Bocconi & Dip. Scienze delle Decisioni & 15 & 32 \\
\hline FIRENZE & Dip. Scienze per l'Economia e per l'Impresa & 16 & 28 \\
\hline ROMA LUISS Guido Carli & Dip. Impresa e Management & 17 & 24 \\
\hline MILANO Bocconi & Dip. Analisi delle Politiche e Management Pubblico & 18 & 29 \\
\hline FERRARA & Dip. Economia e Management & 19 & 33 \\
\hline PERUGIA & Dip. Economia & 20 & 20 \\
\hline TRENTO & Dip. Economia e Management & 21 & 9 \\
\hline TORINO & Dip. Economia e Statistica "Cognetti de Martiis" & 22 & 10 \\
\hline ROMA La Sapienza & Dip. Economia e diritto & 23 & 12 \\
\hline MILANO Bocconi & Dip. Finanza & 24 & 30 \\
\hline MILANO Bocconi & Dip. Management e Tecnologia & 25 & 37 \\
\hline BOLOGNA & Dip. Scienze Statistiche "Paolo Fortunati" & 26 & 15 \\
\hline ROMA LUISS Guido Carli & Dip. Economia e Finanza & 27 & 61 \\
\hline SALERNO & Dip. Scienze Economiche e Statistiche & 28 & 39 \\
\hline VERONA & Dip. Scienze Economiche & 29 & 21 \\
\hline ROMA La Sapienza & Dip. Scienze Statistiche & 30 & 22 \\
\hline
\end{tabular}

We note that the two procedures place the same departments on the podium, representing a robust result. Scrolling through the ranking, however, it is apparent that many departments placed in the top positions in the VQR ranking obtain lower results if assessed following the criteria required to allow the scientific qualification and vice versa, but, in the first 30 departments evaluated with the VQR method, 24 are among the first 30 departments evaluated with the procedure for scientific qualification. However, it should be emphasized that this study aims to compare 2 different evaluation criteria and the results produced just to check whether they attain similar results. The first conclusion that we can draw, in line with the purpose of this article, is that the 2 evaluation criteria are not so far apart in the identification of the departments of excellence.

On the other hand, by analysing the distribution of products of excellence in the territories of the Italian provinces, we can identify those areas where universities are performing best. The following maps show the distribution of the departments of excellence throughout the country. 
Map 1 Class A Products - VQR - Regions

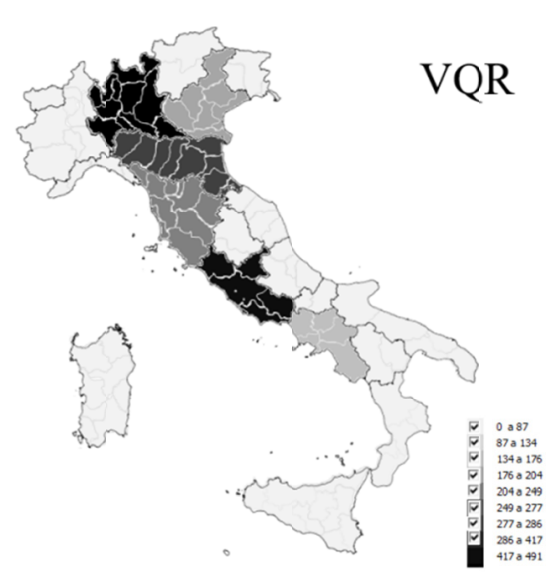

Map 3 Class A Products - VQR - Provinces

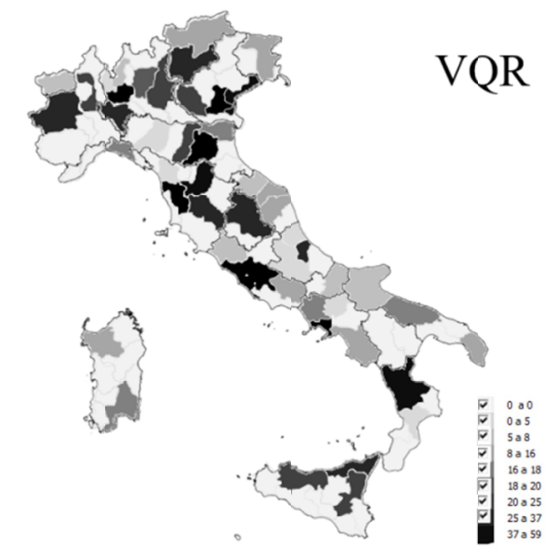

Map 2 Class A Products - ASN - Regions

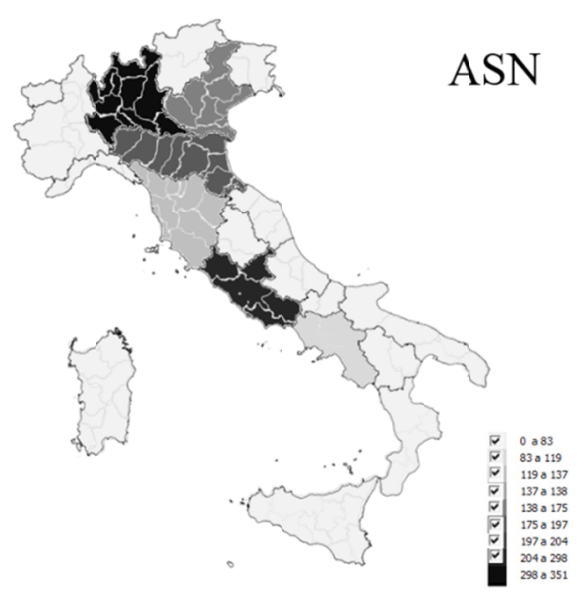

Map 4 Class A Products - ASN - Provinces

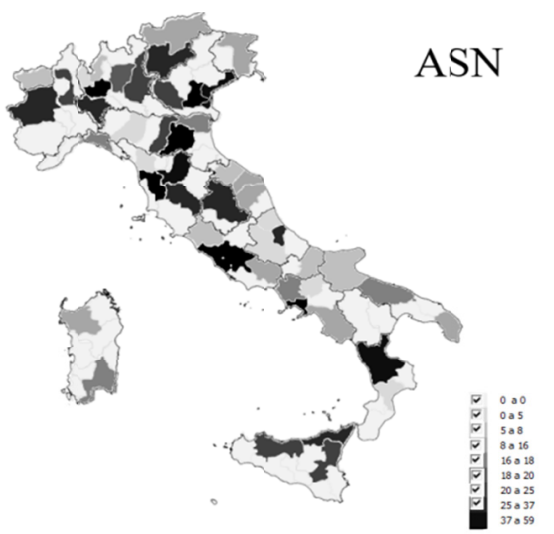

As we can see from the maps, the regions in which the economics departments perform better are Lombardy, Lazio, and Emilia Romagna both if products are assessed with the first methodology (VQR) and if they are assessed through the second (ASN). Analysing the distribution across provinces, we note that some universities in southern Italy have departments of excellence capable of obtaining enviable results. The comparison of geographical areas thus leads to the following conclusion: in the north of Italy, the economics departments obtain the most prestigious results, but small universities in the south of Italy can boast economics departments capable of publishing products of excellence just as in the north. These results are in line with the findings obtained by Abramo, D’Angelo, and Rosati (2016), Ancaiani et al. (2015), Grisorio, Pavolini, and Prota (2017), and Viesti (2016).

\section{Conclusions}

The aim of this paper is to compare two methodologies to assess the scientific activities of the economics departments of Italian universities. These two procedures were created with different purposes and have been implemented with different evaluation approaches. The first procedure, known as the Valutazione della Qualità della Ricerca (VQR), aims to assess periodically the scientific research activities carried out by universities and research institutions. The second procedure, known as the Abilitazione Scientifica Nazionale (ASN), aims to verify the possession of the scientific requisites necessary to be employed as a professor at a university. Both procedures can be interpreted as an attempt to measure the quality of academics' research.

How close are the results if we evaluate the economics departments of Italian universities with these different methodologies? Analysing a sample of about 4,000 articles extracted from the well-known Scopus database and by replicating the evaluation of the products through the 2 methods described above, we can draw the following conclusions: first, the identification of the departments of excellence of the first methodology identifies a podium of departments that represents, albeit in a different order, the first three excellent departments identified by the second methodology; second, considering that in the first 30 departments evaluated with the VQR method, 24 
are among the first 30 departments evaluated with the procedure for scientific qualification, we can consider the results obtained by the 2 methodologies to be fairly close. These results are important in terms of university policies, because, in an environment that is continuously subject to assessment, they could mitigate the doubts about the effectiveness of the methods chosen by the legislator to assess scientific products. Finally, the purpose of this work is to investigate whether the economics departments located in different areas of the country (north, centre, and south) show different performance levels. The comparison of geographical areas indicates that, in the north of Italy, the economics departments obtain the most prestigious results, but small universities in the south of Italy boast economics departments that are capable of publishing products that are as excellent as those in the north. This result can also be useful for university policies, as identifying areas of lower performance can push other scholars to investigate the causes and the policy to invest in reducing them.

\section{References}

Abramo, G., \& D'Angelo, C. A. (2011). Evaluating research: From informed peer review to bibliometrics. Scientometrics, 87(3), 499-514. https://doi.org/10.1007/s11192-011-0352-7

Abramo, G., D'Angelo, C. A., \& Rosati, F. (2016). The north-south divide in the Italian higher education system. Scientometrics, 109, 2093-2117. https://doi.org/10.1007/s11192-016-2141-9

Ancaiani, A., Anfossi, A. F., Barbara, A., Benedetto, S., Blasi, B., Carletti, V., \& Costantini, M. (2015). Evaluating scientific research in Italy: The 2004-10 research evaluation exercise. Research Evaluation, 24, 242-255. https://doi.org/10.1093/reseval/rvv008

ANVUR. (2013). Rapporto Finale Valutazione della Qualità della Ricerca 2004-2010. Luglio. Retrieved from http://www.anvur.org/rapporto

Archambault, É., Campbell, D., Gingras, Y., \& Larivière, V. (2009). Comparing bibliometric statistics obtained from the Web of Science and Scopus. Journal of the Association for Information Science and Technology, 60(7), 1320-1326. https://doi.org/10.1002/asi.21062

Bakkalbasi, N., Bauer, K., Glover, J., \& Wang, L. (2006). Three options for citation tracking: Google Scholar, Scopus and Web of Science. Biomedical Digital Libraries, 3-7. https://doi.org/10.1186/1742-5581-3-7

Deis, L., \& Goodman, D. (2005). Web of Science (2004 version) and Scopus. Charleston Advisor, 5-21.

Falagas, M. E., Pitsouni, E. I., Malietzis, G. A., \& Pappas, G. (2008). Comparison of PubMed, Scopus, Web of Science, and Google Scholar: Strengths and weaknesses. FASEB Journal, 22(2), 338-342. https://doi.org/10.1096/fj.07-9492LSF

Grisorio, M. J., Pavolini, E., \& Prota, F. (2017). Abilitazione Scientifica Nazionale e Valutazione della Qualità della Ricerca. Un confronto a livello territoriale. Scuola Democratica 2/2017.

Horrobin, D. F. (1990). The philosophical basis of peer review and the suppression of innovation. JAMA, 263(10), 1438-1441. https://doi.org/10.1001/jama.1990.03440100162024

Kotsemir, M., \& Shashnov, S. (2017). Measuring, analysis and visualization of research capacity of university at the level of departments and staff members. Scientometrics, 112(3), 1659-1689. https://doi.org/10.1007/s11192-017-2450-7

Landis, J. R., \& Koch, G. G. (1977). The measurement of observer agreement for categorical data. Biometrics, 33(1), 159-174.

Li, J., Burnham, J. F., Lemley, T., \& Britton, R. M. (2010). Citation analysis: Comparison of Web of Science, Scopus, SciFinder, and Google Scholar. Journal of Electronic Resources in Medical Libraries, 7(3), 196-217. https://doi.org/10.1080/15424065.2010.505518

MacRoberts, M. H., \& MacRoberts, B. R. (1996). Problems of citation analysis. Scientometrics, 36(3), 435-444. https://doi.org/10.1007/BF02129604

Meho, L. I., \& Yang, K. (2006). A new era in citation and bibliometric analyses: Web of Science, Scopus, and Google Scholar.

Moed, H. F. (2002). The impact-factors debate: The ISI's uses and limits. Nature, 415, 731-732. doi:10.1038/415731a

Moxam, H., \& Anderson, J. (1992). Peer review. A view from the inside. Science and Technology Policy, 5(1), $7-15$.

Pendlebury, D. A. (2009). The use and misuse of journal metrics and other citation indicators. Scientometrics, 
57(1), 1-11. https://doi.org/10.1007/s00005-009-0008-y

Shashnov, S., \& Kotsemir, M. (2015). Measuring the research capacity of a university: Use of Web of Science and Scopus. In 2nd International Multidisciplinary Scientific Conference on Social Sciences and Arts SGEM2015. Conference proceedings vol. II. Book 1: Psychology and psychiatry, sociology and healthcare, education (pp. 621-628). Sofia: STEF92 Technology Ltd.

Van Leeuwen, T. N., Moed, H. F., Tijssen, R. J. W., Visser, M. S., \& van Raan, A. F. J. (2001). Language biases in the coverage of the Science Citation Index and its consequences for international comparisons of national research performance. Scientometrics, 51, 335. https://doi.org/10.1023/A:1010549719484

Van Raan, A. F. J. (2005). Fatal attraction: Conceptual and methodological problems in the ranking of universities by bibliometric methods. Scientometrics, 62(1), 133-143. https://doi.org/10.1007/s11192-005-0008-6

Van Raan, A. F. J. (2009). For your citations only? Hot topics in bibliometric analysis. Measurement: Interdisciplinary Research and Perspectives, 3(1), 50-62. https://doi.org/10.1207/s15366359mea0301_7

Vieira, E., \& Gomes, J. (2009). A comparison of Scopus and Web of Science for a typical university. Scientometrics, 81(2), 587-600. https://doi.org/10.1007/s11192-009-2178-0

Viesti, G. (2016). Università in declino. Un’indagine sugli atenei da Nord a Sud. Roma: Donzelli.

\section{Copyrights}

Copyright for this article is retained by the author(s), with first publication rights granted to the journal.

This is an open-access article distributed under the terms and conditions of the Creative Commons Attribution license (http://creativecommons.org/licenses/by/4.0/). 